\title{
Perioperative Management of Deventilation Syndrome
}

\author{
Akyol Beyoglu C, Ozdilek A., Erbabacan S.E., Koksal G., Altintas F. \\ Istanbul University, Cerrahpasa Faculty of Medicine, Dept of Anaesthesiology\&ntensive Care, Istanbul, Turkey
}

\begin{abstract}
Introduction:
* Deventilation Syndrome is a rare complication observed in obstructive sleep apnea patients (OSA)

- Severe dyspnea just after cessation of non-invasive mechanical ventilation therapy (NIMV) (1)

- Occurrences of dyspnea, muscle weakness and fatigue (1)

- Disability to perform daily activities at least 30 minutes (2)

* Patient- NIMV device asynchrony, auto-positive end-expiratory pressure, trigger asynchrony, coexisting medical problems

* Muscle tone improves and reverses adverse effects of inaccurate NIMV application
\end{abstract}

\section{Case Definition:}

* 37 years old, morbidly obese patient (body mass index $40 \mathrm{~kg} / \mathrm{m}^{2}$ ) male

* Under continuous positive airway pressure (CPAP) treatment for 3 years

* Suffering from deventilation syndrome that lasts for 30 minutes every morning

* Snoring and daytime sleepiness despite CPAP therapy

* Improvement in muscle tone overcomes the effect of inaccurate CPAP application

* Preoperative arterial blood gas analysis: $\mathrm{PaO}_{2}$ and $\mathrm{PCO}_{2}$ values were $84.1 \mathrm{mmHg}$ and $35.4 \mathrm{mmHg}$ respectively

\section{Perioperative Management:}

General anesthesia

* Unilateral adrenalectomy

* Mask ventilation, intubation periods were uneventful

* Cormack-Lehane Grade 2

* Paracetamol $1 \mathrm{~g}$ and tramadol $100 \mathrm{mg}$ for postoperative analgesia
* Sugammadex $4 \mathrm{mg} / \mathrm{kg}$ was used to reverse neuromuscular blockade

* Successfully extubated after 120 minutes laparoscopic adrenalectomy

* In the recovery room:

-2 $1 /$ min $\mathrm{O}_{2}$ support via facemask in the recovery room

-Hemodynamically stable and did not have any airway obstruction

* Discharged to the ward: Alderete score $>9, \mathrm{PaO}_{2}$ and $\mathrm{PCO}_{2}$ values $97.4 \mathrm{mmHg}$ and $41.7 \mathrm{mmHg}$ respectively

* CPAP therapy was continued during sleep at the night of the operation

* Discharged from the hospital on the 3rd day healthfully

\section{Discussion:}

* Deventilation Syndrome may indicate:

- Inappropriate NIMV treatment, tendency to airway obstruction after general anesthesia

- The most appropriate CPAP pressure and interfaces adjusted for the patient

* Short-acting anesthetics and regional anesthesia if possible

References:

1. Noninvasive Mechanical Ventilation: Theory, Equipment and Clinical Applications. A.M. Esquinas (ed.), DOI 10.1007/978-3-319-21653-9_83. pages 717-23

2. Esquinas AM, Ucar ZZ, Kirakli C. Deventilation syndrome in severe COPD patients during long-term noninvasive mechanical ventilation: poor sleep pattern, hyperinflation, or silent chronic muscular fatigue? Sleep Breath. 2014 May;18(2):225-6. doi: 10.1007/s11325-013-0931-3 